\section{Emerging and Persistent Issues in the Delivery of Asynchronous Non-Traditional Undergraduate Physics Experiments}

\author{
Alec Sithole* iD \\ Missouri Western State University, USA \\ asithole@missouriwestern.edu \\ Edward T. Chiyaka iD \\ Kent State University, USA \\ echiyaka@kent.edu \\ Fidelis Manyanga \\ Salem State University, USA \\ fmanyanga@salemstate.edu
}

Davison M. Mupinga iD

Kent State University, USA

dmupinga@kent.edu

\begin{abstract}
Remote physics laboratory activities are common tools of use in physics in traditional, online, and distance education to enhance student learning. Although these offerings necessitated by technological advances, spur innovation and improvement in undergraduate physics education, their use as stand-alone substitutes for instructor-guided physical laboratory experiments remain the center of debate and research. This paper for instructor-guided physical laboratory experiments remain the center of debate and research. This paper
discusses the effectiveness of the current pedagogic issues in the delivery and learning of four different types of remote introductory undergraduate physics laboratory activities, the breakthroughs, and the areas that require further investigations. The instructional issues include experiment preparation and design, student engagement, guidance, and safety. This review noted the positive impacts of stand-alone remote physics lab activities on mostly undergraduate non-physics majors, partly due to the limited number of institutions currently conferring complete online/distance physics degrees worldwide. We recommend further studies on the effect on physics students who end up in experimental physics-related careers.
\end{abstract}

\section{Keywords}

computer-simulations; distance physics education; home-based physics labs; online learning; remotelycontrolled laboratories; asynchronous; virtual labs

•Received 19 November $2018 \bullet$ Revised 29 November $2018 \bullet$ Accepted 15 April 2019

\section{Terminology}

The lack of consistency and standards in literature on the definitions of non-traditional physics lab activities have been noted by Faulconer and Gruss (2018). The authors identified three groups of non-traditional laboratory experiments. Due to the marked pedagogic differences between simulations and virtual labs (Keller, 2008), in this communication, four categories of asynchronous physics lab activities and their intended meanings are used:

- Computer-simulated labs - computer-aided animations and interactive activities that mimic physical experiments. The data from these activities is not real but generated by computer models.

- Home-based labs - physical experimental activities involving the use of physical laboratory equipment (real lab equipment, lab kits, etc.) or improvised materials (e.g. house utensils).

- Remotely-controlled labs - lab activities that involve students performing physics experiments and collecting data remotely via a computer interface.

- Virtual labs - activities in which students watch pre-recorded videos of physics experiments and to complete assigned tasks.

\section{Introduction}

Learning physics through online, remote, or distance learning is mostly restricted by the need for laboratory experience (Doolan, Tabirca, \& O'Sullivan, 2006). The increasing demand for distance and online education is bringing new challenges and opportunities in education (National Research Council, 2013), particularly in courses that have compulsory laboratory components. In physics education, laboratory experiments are used to demonstrate and validate theories and laws of physics (Sharma, Das, \& Kumari, 2009). The current rapid migration from the traditional to the online and distance learning environments continues to generate a plethora of challenges, most of which are non-existent in the traditional on-campus brick-and-motor classroom set-ups. Laboratory activities remain an essential component of physics courses and can be difficult to implement in online and distance courses. In some cases, students who take online physics classes maybe required to attend a compulsory residential school where laboratory work maybe covered in a short time resulting in information overload (Turner \& Parisi, 2008). However, new distance learning approaches seek to address such challenges.

As educational technologies continue to evolve, new issues emerge. Even experienced online educators are still searching for solutions to the current online and distance education laboratory delivery challenges. For example, high diversity enrichment (in terms of student academic readiness, or lack thereof, culture, time zones, discipline, computer technology skills, etc.) calls for the need to develop inclusive pedagogical approaches resulting in new complexities and challenges to the online academic enterprise, worldwide. A study published by the Indira Gandhi 
National Open University (Sharma, Das, \& Kumari, 2009) indicated that delivering and learning lab activities offer challenges to both the teachers and learners in distance education.

\section{Aims of the Study}

This study explored the critical and contemporary issues in the delivery of computer-simulated, remotely-controlled, and virtual labs through asynchronous online and distance physics education programs. The two primary aims of the study were to:

a) highlight the successes, opportunities, and challenges of using each type non-traditional physics laboratory activities; and to

b) identify and recommend areas of improvement and the steps needed to address the challenges.

\section{Statement of the Problem}

The need to engage students in a sequence of scientific practices that includes both theoretical and practical training cannot be over-emphasized, particularly in physics, which is mostly experimental in nature. Currently, physics is one of the areas in which successfully offering a complete online bachelor's degree remains difficult due to the practical components of the subject. The need for student laboratory experience under such circumstances continues to pose challenges to physics educators. Faulconer and Gruss (2018) noted that lab activities may have different intended purposes - one in which the learner is expected to apply the knowledge, and one which aims to reinforce the course content. This means that the learners' expectations and learning experience are not generalizable among students enrolled in general physics courses. Zwickl, Finkelstein and Lewandowski (2013) raised questions about the amount of guidance considered adequate for the student to develop these scientific practices and their ability to transfer those skills to solve real physical problems. However, the delivery and technology used in physics labs continue to change as new technology emerges, which increases the need to continuously evaluate the way students learn physics (Krusberg, 2007). Nevertheless, these changes also help physics educators better prepare students for highly technical careers as modern economies become more heavily dependent on science and technology (Wieman \& Perkins, 2005).

There are three important questions for online and distance education physics faculty; What issues do instructors and students encounter with non-traditional physics labs in the face of rapid technological and digital advancement? Do non-traditional lab experiences impart the appropriate laboratory techniques and scientific reasoning? Which areas require improvements, and/or what is the future research direction?

\section{Research Methods}

Studies included in this study were identified through keyword searches of the Web of Science a database that provides information to examine the publication trends in Science, Technology,
Engineering, and Mathematics (STEM) education. Other major online databases such as Google Scholar and Scopus were also manually searched. These multidisciplinary search data bases were considered ideal for this study since non-traditional physics laboratory activities are interdisciplinary and commonly published in STEM journals. The major key phrases used to gather literature material were: "physics simulations"; "online physics labs"; "physics animations"; "web-based physics labs"; "physics lab kits"; "physics home experiments"; homebased physics labs"; "at-home physics experiments"; "improvised home physics labs"; "remote physics labs", "physics experiments at a distance"; "real remote physics laboratories"; "remote lab teaching"; "virtual physics experiments, video", "physics experiments videos"; and "videobased labs." Studies involving the four classes of labs described above were considered and analyzed in this study. Dissertations and unpublished materials were not explored.

\section{The Status of Remote Physics Laboratories}

In physics education, gaining the experimental skills is equally important to the understanding of the theoretical material in the course. According to Badjou and Dahmani (2013), the major objectives of laboratories are for the student to gain knowledge of the: a) use of instruments/sensors in taking precise and accurate measurements; b) strengths and limitations of theoretical models as predictors of physical processes; c) developments and improvements of experimental methods and design; d) processes of analysis of data, interpretation of the results and technical communication; e) safety and health issues in laboratories; and f) ethical standards and integrity expected when performing laboratory experiments.

As the enrollments in online and distance education continue to increase, one of the sticking challenges in physics is the delivery of laboratory experiments. Currently, online and distance physics education utilizes four types of tools to fulfill physics lab requirements: a) online computer simulations; b) home/lab kits experiments; c) remotely accessed laboratories; and d) virtual labs utilizing pre-recorded lab sessions (Badjou \& Dahmani, 2013). In all these remote lab activities, the level of knowledge of the experimenter (student) is not well known. Issues that arise at this point include predicting the students' ability to understand the theory of the lab provided in the lab handout, the material, and the technology (such as software) used in the experiment. For example, quite often, computer-aided lab activities require a certain level of computer use knowledge. While it is commonly a requirement for a student to complete the basic computer knowledge test involving the use of Word processor, Excel, internet and email browsing, the extend to which this knowledge assessment can predict student success in completing these experiments need further investigations. In non-collaborative lab activities, which is often the case with asynchronous and distance education, the extent to which the student struggles to complete the activities remain uncertain. In addition, while the constantly changing technology requires the student to stay up-to-date with advances, web links, and data acquisition software commonly break without notice. In the sections below, four different modes of asynchronous non-traditional lab activities are discussed, including their strengths and flaws. 


\section{Computer-Simulated Experiments}

The use of computer simulations in laboratory activities is expanding rapidly with commercial entities and institutions taking advantage of the improvements in technology to reach out to many students (Jones, 2018). Computer simulations/animations continue to play many roles in physics laboratories, such as pre and post-laboratory exercises/animations, data collection and analysis. Computer-simulated labs involve one or a combination of the interactive activities (animations, interactive graphics, and imagery) and virtual field trips (e.g. interactive maps, photographs, etc.) (Holmes, Roberts, Snow, \& Pujana, 2010). Some of the commonly used computer-simulations labs include those found on: Java-Programs on Physics, MERLOT Simulation Collection, General Physics Java Applets, Physics Online Labs, PhET Interactive Simulations, Open Science laboratory, North American Network of Science Labs Online, and Physics Lab. These activities have their own strengths and weaknesses. Tüysüz (2010) found that these types of virtual laboratories had a positive impact on students' achievements and attitudes, particularly in poorlyresourced and large enrolment schools. These computer simulations allow students to explore potential situations that would be unsafe, too expensive, difficult and time-consuming to accomplish in a physical laboratory. They are safe, convenient, controllable, and can enhance active learning (Akpan, 2001).

The major drawback is that computer-simulations are highly dependent on computer technology, such that with rapid changes in technology (which often occur without notice), simulation software require continuous updates. The arduous task of developing and sustaining these computer activities and the need for high level of computer programming knowledge (Atkins, Brown, \& Hammond, 2007) forces most instructors to rely on externally hosted and created computer-simulated labs. In this case, the instructor does not have control of the architecture, the links, and maintenance of these labs. Moreover, when students experience technical problems, even the instructors can only offer very limited or no meaningful assistance. Additionally, according to Bell and Smetana (2008, pp. 23-32), simulations are simple mathematical models that do not represent real data. Understanding the differences and similarities between real data and simulated data is a critical component of the learning process. That experience may be missed if students rely on simulations only. Thus, if not carefully designed, technology (and not content) may become the major focus in computer-simulated laboratory experiments.

\section{Remotely-Controlled Experiments}

Remotely triggering experiments in an actual lab and collecting the data via a computer interface is another way of enabling students to complete their lab experiments. Remote-controlled physics laboratories involve interacting the learner's computer with real instruments to share experimental data via some form of telecommunication (Khazri, et al., 2017). Through this approach, a user in one location, connects their computer via the internet to a real experiment being carried out in a different location. The use of various remotely-controlled experiments have been demonstrated and reported in several studies (Khazri et al.,2018; Bingol \& Aydogan, 2012; Sládek, Pawera \& Válek, 2011; Cooper, Donnelly, \& Ferreira, 2002). Examples of these lab activities include: Remote Farm, RCL-Portal, North American Network Of Science Labs Online (NANSLO), iLabs, iSES, The NetLab remote laboratory project, Universal Environment for Delivering Remote-Laboratories within the STEM Disciplines, Integrated Laboratory Network, Weblabdeusto, iLough-Lab, and many others. Remote laboratories allow learners to operate equipment, and to measure and view experiments on real laboratory experiments from their own geographical locations. This approach has the advantage that it gives students access to real data as compared to real simulations. Moreover, these labs provide an alternative means for students to conduct experiments using physical laboratory equipment while off site and complete the lab activities at their own convenience. Khazri et al., (2018) reported improved student interest and self-paced learning. Another added advantage is that a single complex and expensive equipment can be easily shared among several students, which significantly reduces institutional spending on purchasing and maintaining the equipment (Cooper et al., 2002). In addition, the advent of computer-assistive technologies can be integrated into the laboratory interface to assist students with disabilities who may not be able to attend physical labs.

The downside is that the instructor/technician is responsible for setting-up and tearing all the labs, so the students will not have the knowledge and experience of setting-up and running the experiment. In addition, for large classes and many labs, the challenge would be to integrate different types of lab equipment into this type of lab environment (Khazri, et al., 2017). While some electronic/electrical circuit labs have been successfully integrated into various programmable platforms, not every laboratory equipment can be easily automated to for telemetry. For example, some mechanical experiments still pose great challenges to connect to computerized interfaces. Developing a generic platform to allow automated data acquisition using existing laboratory equipment remains a key obstacle in online and distance science / engineering education (Khazri et al., 2018).

\section{Physical Home-Based Experiments}

The desire to engage students in real experiments in distance and online science education is one of the major push factors behind the current drive towards the use of home laboratory experiments. Various approaches are often used such as doing experiments using common household utensils (Bhukuvhani et al., 2012), using conventional laboratory equipment, and commercially acquired science lab kits. The use of home equipment (improvisation) and schoolsupplied conventional lab equipment have been used in distance education for some time (Bhukuvhani et al., 2010). These approaches continue to experience some challenges as some students may not have the material or equipment needed to complete the experiments. Even when every student can get the house utensils to complete the experiment, the student data would be heterogeneous, making it difficult for peer-collaborative discussion. In addition, the rising cost of lab equipment and student enrollment in distance education continue to make it difficult for 
institutions to supply or rent the equipment to the students (Faulconer \& Gruss, 2018). In the latter, lending conventional lab equipment to students can potentially lead to legal challenges in case of breakage, safety issues or/and accidents.

Because of the rising cost of lab equipment and increasing demand for online physics courses, some institutions require the student to purchase the equipment from commercial vendors (Faulconer \& Gruss, 2018). This approach cuts the institutional cost of buying and maintaining the real lab equipment (Lynch \& Ghergulescu, 2017). To the student, the additional cost may contribute to additional student debt. The downside is that students who cannot afford to purchase the equipment may choose to forgo those lab experiments and lose the laboratory credit component of the course. Unfortunately, the real impact on students' cost of education and academic success rate is currently not well known.

In the U.S., the use of commercially supplied lab kits to complete lab activities is gaining momentum. The cost per unit varies significantly, depending on the quality and commercial vendor (Faulconer \& Gruss, 2018). Currently, these vendors do not offer the option to rent equipment, so the student will end up disposing the equipment when they no longer need it. In some experiments, such as the ones involving high alternating current and voltage, safety becomes a major concern (Badjou \& Dahmani, 2013).

\section{Virtual Physics Labs}

In this approach, students view recorded videos of the experiments on a computer screen to complete the physics lab activities. Virtual physics labs have advanced to the point where the video narration, experimental procedures, data collection process, and data analysis are combined to enhance active learning. Examples of virtual physics labs include: Interactive Video Vignettes (Teese, Laws, \& Koenig, 2016), PhysLab, and PhysTrack (Hassan \& Anwar, 2017), among others. Setting up these experiments requires recording the video measurements, the demonstration, and the audio communication. This flexibility offers students more opportunities to learn physics despite their geographical location and time zones (Doolan, et al., 2006). Furthermore, the ability to perform multiple/repeated runs gives these labs an added advantage over traditional physical labs. Another benefit is that there are no student safety concerns since dangerous/harmful labs can be completed based on pre-recorded videos (Lynch \& Ghergulescu, 2017).

While these labs offer many advantages, their "lack of real-life feel", low/no emphasis on lab safety, and the absence of "poor or uncharacteristic data" remain the major concerns (Lynch \& Ghergulescu, 2017). According to Lynch and Ghergulescu (2017), "Students have raised concerns with not being able to handle real equipment and feeling as if they are losing out on some stages of practical training available in traditional labs." Also, a survey study by Brodeur, Braithwaite, Kolb and Minocha (2016) identified eight major concerns from students: 1) lack of physical practice; 2) technical issues in badly-designed computer programs; 3) lack of freedom to use different approaches as opposed to the use of one procedure; 4) relevance and acceptance of virtual labs in the physics discipline; 5) absence of real-world data collection experience; 6) absence of synchronous communication; 7) absence of experience to set-up the experiments as opposed to the use of preset experiments; and 8) the absence of troubleshooting experience.

While the technology already exists to transform some of the traditional labs into the virtual environment, such as PhysLab (Hassan \& Anwar, nd), Phys'Track (Hassan \& Anwar, 2017), Interactive Video Vignettes (Teese et al., 2016), among others, some faculty may have difficulties assisting students whenever students experience technical problems. For example, the PhysLab and PhysTrack videos operate on a MATLAB-based environment, which requires advanced computer skills to change the code. Furthermore, operating the virtual learning technology may require both the faculty and technical personnel to jointly assist students. The challenge is that, not every university or college has physics technical personnel to deal with that level of technology. For small colleges and universities that do not have laboratory technicians, the burden to troubleshoot technical problems falls onto the physics faculty. Also, while the proliferation of commercial and open source virtual physics labs on the internet is on the rise, using them successfully may require understanding the underlying technology.

\section{Discussion}

In the wake of technological advancements and changes in the way physics education is delivered, continuous efforts must be directed towards improving the learning environment, objectives, and outcomes. One such step is to understand the successes and weaknesses of the current pedagogic approaches in non-traditional laboratory activities and identifying areas that require further improvements/investigations.

\section{Breakthroughs}

Offering lab experience to students through asynchronous online and distance education provides a more flexible schedule to students in different geographic locations. Computer simulations have proved to be highly interactive and can be used to perform complex experiments. In addition, offsite labs can be completed over a relatively longer time than onsite labs, and thus give the student more lab experience (Al-Shamali \& Connors, 2010). Increased lab time has been the driving force behind the use of simulations and sending the lab equipment to the student's home (Lynch \& Ghergulescu, 2017). For schools with limited resources, the use of lab simulations and home lab kits offer alternative student lab experience. Similarly, computergenerated simulations allow students to explore complicated and hazardous experiments, and to perform repeated measurements in a short time (Kennepohl, 2001). According to Al-Shamali and Connors (2010), the absence of assistance to distance learners forces them to increase their efforts to complete the lab, which is considered an important component of active learning. In addition, the use of virtual labs enables the institutions to share their lab resources (Wolf, 2010). In turn, 
offering virtual and remotely controlled labs for introductory courses creates more lab space for advanced courses (Faulconer \& Gruss, 2018).

Computer-simulated online physics labs on electric circuits have been reported to increase students' interest in physics (Gryczka et al., 2016). It must be noted that these students completed the activities under the guidance of their teachers, but the effect may not be generalizable to include asynchronous online and distance education. Similarly, computer simulated physics experiments have been reported to be effective for conceptual understanding of physics particularly in lecture, class activities, labs, and homework (PhET Interactive Simulations, nd; Zacharia \& Olympiou, 2011).

Asynchronous online or distance labs significantly make it easier to offer physics courses through online and distance education, providing the much-needed course flexibility (Badjou \& Dahmani, 2013; Bhukuvhani et al., 2012), particularly for adult and working students. The major outcome of all different types of labs is to mimic or perfectly match the physical face-to-face lab activities. Although the number of colleges and universities delivering physics experiments remotely remains low, more institutions are now accepting fully online/distance learning physics course credits. Similarly, several regionally accredited public and private institutions now offer fully online/distance physics courses. As more students complete non-traditional lab-based physics courses and join physics-related careers, there is a likelihood that the popularity of courses will continue to increase in the future.

\section{Challenges/Constraints}

As noted earlier, each mode of lab experience has its own benefits and challenges. There is concern about the level and the quality of the use of home experiments using simulations and physical equipment (Lynch \& Ghergulescu, 2017). Computer simulations require students to have basic digital skills and access to high-speed internet. They must also have access to a computer with certain minimum specifications (typically, recent operating system, good amount of RAM, Microsoft Word and spreadsheet programs, headphones/speakers, and webcam). In addition, one of the major objectives for experimentation is to learn the treatment of physical errors during measurements and finding ways to reduce them during experimentation or research. That aspect of learning is often missed when using simulations.

Students require some level of learning support during the laboratory activities. The absence of immediate assistance (such as from the instructor, the technician or the lab partner) (Faulconer \& Gruss, 2018), which is often available in physical on-campus labs, is another downside of home-based labs. Al-Shamali and Connors (2010) noted that overreliance on simulations at the expense of real experiments could mislead students' view of how scientific knowledge is generated. The high cost of buying and shipping equipment is a major concern for distance education (Kennepohl, 2001). Currently, most commercial vendors sell, but do not rent the equipment to students. This means that once the student completes the course, they will have to keep or dispose the equipment. According to Al-Shamali and Connors (2010), the use of lab kits at home is relatively new, and currently there are no standards that govern their use to achieve the desired learning outcome. Likewise, physical home experiments are limited to safe and inexpensive versions of the ones used in a traditional class, which limits the complexity of the labs that can be done through distance education. In some complex experiments, the pedagogical practices for delivering traditional labs remotely is not yet well understood.

Furthermore, the success of students in asynchronous online learning and distance education is dependent on the level of instructor-student engagement. The absence of instant feedback in asynchronous learning environment (Faulconer \& Gruss, 2018) has the potential to affect the learners' motivation and performance. Student guidance is commonly needed in experimental set-up, data collection, analysis, and report writing. Home-based lab activities may involve various aspects beyond data collection and data post-mortem activities, which include both student safety and other precautions. Thus, student-instructor engagement is critical for hands-on labs. Typically, in the on-campus brick-and-motor laboratories, students complete and discuss their lab activities in groups, but in asynchronous remote education, the geographic location inhibits that level of interaction.

\section{Future Research Directions}

The use of non-traditional physics experiments in online and distance education has been a great advancement over the past decade. However, there still exist some knowledge gaps on their impact on student learning experience and successful application of the knowledge in their career technical performance (Lateef, 2010). Improving the quality and delivery of online and distance labs requires adequate research to determine if "laboratory experiences properly prepare students for more advanced laboratory experiences" (Faulconer \& Gruss, 2018), and the level of student learning experience and its long-term career impacts. There is need to provide quality guiding instructions on each lab as most students still experience problems understanding the concepts learned in the lab and how to process the collected data. It is also equally important to determine how students are affected by the high cost of purchasing the equipment and the learning experiences of those who purchase the equipment.

Furthermore, commercially-supplied non-traditional lab equipment and platforms are continuously evolving. This calls for a continuous review of the standards and quality of these experiments to ensure every student is afforded an equal opportunity to learn. For example, in the case where the laboratory activities rely heavily on audio and video transcripts, such as in virtual labs, more comprehensive studies are required to understand the extent to which the needs of students with visual and audio impairments are addressed. Another area that has not been explored extensively in physics is determining the effect of blending all the four non-traditional lab activities in each laboratory activity on student learning. For example, how would providing 
a virtual lab with pre-recorded videos and simulations as pre-lab preparation for a physical homebased physical laboratory activity affect the student's physics laboratory experience? In a webbased distant engineering education program, this blended model was found to be effective in enhancing student learning experience (Cavus \& Ibrahim, 2007).

Students' learning experiences must continue to guide the design of both the equipment and the experiments. It would be desirable to understand student characteristics and their needs, comparison of long-term impacts between peer collaboration and individual effort in synchronous and asynchronous environments, respectively. Determining the most favorable conditions and sequence to make these labs effective on student learning is another direction that future research can take. Akpan (2001) also raised questions about the long-term impacts of nontraditional labs. Since the needs of learners are diverse, lab experiments must be designed with the aim of addressing student learning needs and disability issues. Moreover, more advanced research is recommended to compare the long-term impacts of the use of remote and conventional labs on student career performance. Pertinent questions, therefore, arise. Are the remote labs a good fit for all students taking physics (prospective physics teachers; computer science majors; pre-engineering students; prospective theoretical and experimental physicists, mathematicians, etc.)? What would be the performance level of physics graduates in experimental/research-related fields if they take remote labs as part of their laboratories through asynchronous online or distance education environment? Which programs mostly report academic and career success directly linked to the use of non-traditional lab activities? Harms (2000), also noted the need to understand the extent to which these labs in physics education address the lab objectives; how to address those restrictions; and identify the areas that require future improvements.

Another persistent argument is that technology is handing over more control of learning to the student, and the faculty role is continuously changing. While this change is experienced by online and distance education instructors across various disciplines, achieving the desired learning outcomes in physics laboratory experiments becomes more difficult. The type and level of faculty skills needed to effectively deliver these experiments is best determined from the students' learning experiences. Jones (2018) also pointed out that while some studies show that nontraditional labs improve some students' test scores, further studies are needed to understand the impact of new technology labs and how they can mimic physical laboratory experiments.

\section{Limitations of Study}

The search phrases used in this study may not be exhaustive. Due to the interdisciplinary nature of non-traditional physics lab experiments, several other databases may exist with additional information. Moreover, these search terms have not been tested for statistical significance in generating the required literature required in this kind of study.

\section{Conclusion}

Online and distance physics education is expanding rapidly, and so is the need to address the laboratory challenges in those learning environments. The expansion is partly driven by the desire to cut institutional costs, offer flexible and accessible education to students, make student learning experience meaningful and find alternative ways of training the new generation of future technologically-driven scientists. While many steps have been and are being, taken to address some of the challenges and limitations of these labs, their delivery remains the most significant challenge for physics educators in asynchronous distance and online education. Barriers to the use of remote physical lab equipment include the lack of institutional resources to provide equipment to every student particularly in cases where sophisticated equipment is needed; inability to ensure student safety in the absence of the instructor; and the inability to predict students' technical knowledge needed to succeed in online or distance learning environments. Nevertheless, simulations, virtual, remote, and home-based laboratory experiments continue to play important roles in physics education. Institutions can create partnerships with commercial vendors to ensure the compliance of non-traditional labs to educational standards. Also, renting or recycling equipment would significantly help students to reduce the cost of acquiring physics equipment for home-based experiments. In addition, the blending of different types of labs may potentially enrich the students' experimental knowledge and experience in physics.

\section{Conflict of Interest}

All the authors listed on this manuscript have no affiliations with organizations or commercial entities that develop, distribute or sell physics equipment, science kits, virtual, remotely-controlled or simulation labs. Authors have no financial interest, no conflict of interest or perceived conflict of interest in the subject matter or materials discussed in this manuscript.

\section{References}

Al-Shamali, F., \& Connors, M. (2010). Low cost physics home lab. In Kennepohl, D. \& Shaw, L. (Eds.), Teaching Science at a Distance (pp. 131-146). AU Press. Retrieved from http://citeseerx.ist.psu.edu/viewdoc/download?doi=10.1.1.210.3774\&rep=rep1\&type=pdf

Atkins, D., Seely Brown, J., \& Hammond, A.L. (2007). A review of the open educational resources (OER) movement: Achievements, challenges, and new opportunities. Retrieved https://hewlett.org/wpcontent/uploads/2016/08/ReviewoftheOERMovement.pdf

Akpan, J.P. (2001). Issues associated with inserting computer simulations into biology instruction: A review of the literature. Electronic Journal of Science Education, 2(3).

Badjou, S., and Dahmani, R. (2013). Current status of online Science and Engineering. Education. Journal of Online Engineering Education, 4(1), Article 3.

Bell, R.L., \& Smetana, L. (2008). Using computer simulations to enhance science teaching and learning. In R.L.Bell, J. Gess-Newsome, \& J. Luft (Eds.), Technology in the secondary science classroom. Arlington, VA: NSTA Press. Pp 23-32.

Bhukuvhani, C., Kusure, L., Munodawafa, V., Sana, A. \& Gwizangwe, I. (2010). Pre-service Teachers' use of improvised and virtual laboratory experimentation in Science teaching. International Journal of Education and Development using ICT, 6(4), 27-38. 
Bhukuvhani, C., Mupa, M., Mhinshi, M., and Dziva, D. (2012). Science practical work instructional technologies and open distance learning in science teacher learning: A case in Zimbabwe. International Journal of Education \& Development using Information and Communication Technology, 8(2), 17-27.

Bingol, O., \& Aydogan, O. (2012). Web based remote controlled electrical motor laboratory used as educational tool. Prieglad Elektrotechniczny, 88, 342-346.

Brodeur, M., Braithwaite, N., Kolb, U., \& Minocha, S. (2016). Improving undergraduate engagement with online labs: Student priorities and strategies for virtual and remote investigations. In L.-J. Thoms \& R. Girwidz (Eds.), Selected Papers from priorities and strategies for virtual and remote investigations. In L.-J. Thoms \& R. Girwidz (Eds.), Selected Papers from
the 20th International Conference on Multimedia in Physics Teaching and Learning (pp. 27-34). Mulhouse:

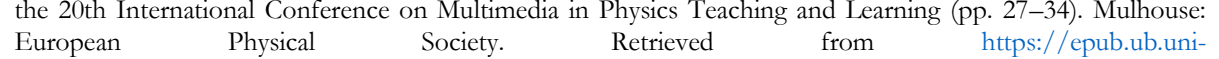
European Physical Society. Retrisc
muenchen.de/28963/1/MPTL2015_Selected_Papers.pdf

Cavus, N. \& Ibrahim, D. (2007). Is blended learning the solution to web-based distant engineering education? International Educational Technology (IETC) Conference (7th, Nicosia, Turkish Republic of Nortbern Cyprus, May 3-5, 2007. Retrieved from https:// files.eric.ed.gov/ fulltext/ED500189.pdf

Cooper, M., Donnelly A., \& Ferreira J.M. (2002). Remote controlled experiments for teaching over the internet: A comparison of approaches developed in the Pearl Project. Proceedings of the 19th. Annual Conference of Australasian Society for Computers in Learning in Tertiary Education. Retrieved from Society for Computers in Learning in Tertiary Educt
$\mathrm{http}: / /$ www.ascilite.org/conferences/auckland02/proceedings/papers/112.pdf

Doolan, D., Tabirca, S., O'Sullivan, C. (2006). Virtual science lab (VSL) an educational tool for demonstrating science experiments. Proceedings of the 5th RoEduNet International Conference, At Sibiu, Romania. Retrieved from http://www.physics.ucc.ie/staff/14\%20-\%2032_NER_NAT_15.PDF

Faulconer, E. K., \& Gruss, A. B. (2018). A Review to Weigh the Pros and Cons of Online, Remote, and Distance Science Laboratory Experiences. The International Review of Research in Open and Distributed Learning, 19(2).

Gryczka, P., Klementowicz, E., Sharrock, C., Montclare, J.K. (2016). Interactive online physics labs increase high school students' interest. Journal of Technology and Science Education, 6(3), 166-187.

Harms, U. (2000). Virtual and remote labs in physics education. 2nd European Conference on Physics Teaching Engineering $\begin{array}{lr}\text { Education, } & \text { Budapest. }\end{array}$ https://pdfs.semanticscholar.org/62be/5ec4a9060ba2594ce792316c8f52dc3a8797.pdf

Hassan, M. U., \& Anwar, M. S. (nd). PhysTrack. Lahore University of Management Sciences (LUMS), Lahore, Pakistan. Retrieved from https://github.com/umartechboy/PhysTrack

Hassan, M. U., \& Anwar, M. S. (2017). 'PhysTrack': a Matlab based environment for video tracking of kinematics in the physics laboratory. European Journal of Physics, 38(4), pp. 045007. doi: 10.1088/1361-6404/aa747a.

Hollebeke, N. (nd). Transferability and articulation agreements for online science lab courses. Carolina Distance Learning. Retrieved from http://landing.carolina.com/Global/FileLib/dl-content/dl_articulation_agreement.pdf

Holmes, A., Roberts, S., Snow, E., \& Pujana, I. (2010). Using data to teach Geology in college-level online classes. In Workshop, Teaching Geoscience Online - A Workshop for Digital Faculty. Retrieved from http://serc.carleton.edu/NAGTWorkshops/online/platforms.html

Jones, N. (2018). Simulated labs are booming: Blowing up your lab is usually discouraged, but it's part of the experience when you're learning online. Nature, 562, S5-S7. doi: 10.1038/d41586-018-06831-1

Keller, H. (2008). Science labs: Virtual versus simulated. THE Journal: Transforming Education Through Technology, Public Sector Media Group. Retrieved from https://thejournal.com/articles/2008/05/05/science-labs-virtual-versussimulated.aspx

Kennepohl, D. (2001). Using computer simulations to supplement teaching laboratories in chemistry for distance delivery. Journal of Distance Education, 16(2), 58-65.

Khazri, Y., AL Sabri, A., Sabir, B., Toumi, H., Moussetad M., \& Fahli, A. (2018). Remote control laboratory experiments in physics using LabVIEW. International Journal of Information Science \& Technology, 1(1), 11-16.

Krusberg, Z. (2007). Emerging technologies in physics education. Journal of Science Education \& Technology, 16(5), 401-411. doi: 10.1007/s10956-007-9068-0

Lateef, F. (2010). Simulation-based learning: Just like the real thing. Journal of Emergencies, Trauma, and Shock, 3(4), 348-52.
Lynch, T. and Ghergulescu, I. (2017). Review of virtual labs as the emerying technologies for teacbing STEM Subjects. Proceedings of the 11th International Technology, Education and Development Conference, March 6-8, 2017, Valencia, Spain. Retrieved from http://www.newtonproject.eu/wp-content/uploads/2016/02/review-of-virtual-labs-asthe-emerging-technologies-for-teaching-stem-subjects-1.pdf

National Research Council (2013). Educating engineers: Preparing 21st century leaders in the context of new modes of learning. Washington, DC: The National Academies Press. Retrieved from http:/ / www.nap.edu/catalog/18254/educating-engineers-preparing-21st-century-leaders-in-the-context-ofnew-modes-of-learning

PhET Interactive Simulations (nd). How PhET simulations are designed, and the research process of refining the simulations to best promote learning. PhET: Research and Development. PhET Interactive Simulations. University of Colorado. Retrieved from https://phet.colorado.edu/en/research\#design

Sharma, O.P., Das, M., \& Kumari, R. (2009). Critical Issues in Distance Science Lab Practicals: A Study. National Centre for Innovation in Distance Education, Indira Gandhi National Open University. Retrieved from http://www.ignou.ac.in/userfiles/3_\%20Critical\%20Issues\%20in\%20Distance $\% 20$ Science $\% 20$ Lab $\% 20$ Practi cals.pdf

Sládek, P. Pawera L.\& Válek (2011). Remote laboratory-new possibility for school experiments, Procedia Social and Behavioral Sciences, 12(1), $164-167$.

Teese, R.B., Laws, P.W., \& Koenig, K. (2016). Interactive video Vignettes. In L.-J. Thoms \& R. Girwidz (Eds.), Selected Papers from the 20th International Conference on Multimedia in Physics Teaching and Learning (pp. 11-16). Mulhouse: European Physical Society. Retrieved from https://epub.ub.unimuenchen.de/28963/1/MPTL2015_Selected_Papers.pdf

Turner, J., \& Parisi, A. (2008). Take-home physics experiment kit for on-campus and off-campus students. Teacbing Science, $54(2), 20-23$.

Tüysüz, C. (2010). The effect of the virtual laboratory on students' achievement and attitude in chemistry. International Online Journal of Educational Sciences, 2(1), 37-53. http://doi.org/13092707

Weiman, C., \& Perkins, K. (2005). Transforming Physics Education. Physics Today, $58(11), 36$

Wolf, T. (2010). Assessing student learning in a virtual laboratory environment. IEEE Transactions on Education, 53(2), 216-222. doi: 10.1109/TE.2008.2012114

Zacharia, Z.C., \& Olympiou, G. (2011). Physical versus virtual manipulative experimentation in physics learning. Learning and Instruction, 21, 317-331.

Zwickl, M. B, Finkelstein, N \& Lewandowski, H. J. (2013). A framework for incorporating model-based Inquiry into physics laboratory courses" arxiv:1301.4414v1 [physics.ed-ph]. Retrieved From http://www.colorado.edu/physics/educationissues/zwickl/resources/zwickl_framework_for_modelbased_in quiry.pdf 